\title{
Ethnologies
}

\section{Le patrimoine immatériel en France entre renouveau muséographique et " territoire de projet »}

\section{Dominique Poulot}

Volume 31, numéro 1, 2009

Passages

URI : https://id.erudit.org/iderudit/038504ar

DOI : https://doi.org/10.7202/038504ar

Aller au sommaire du numéro

\section{Éditeur(s)}

Association Canadienne d'Ethnologie et de Folklore

ISSN

1481-5974 (imprimé)

1708-0401 (numérique)

Découvrir la revue

Citer cet article

Poulot, D. (2009). Le patrimoine immatériel en France entre renouveau muséographique et « territoire de projet ». Ethnologies, 31(1), 165-200. https://doi.org/10.7202/038504ar
Résumé de l'article

La signature de la convention du Patrimoine culturel immatériel par la France en 2006, ouvre, aux yeux d'une large partie de la communauté de l'ethnologie française, une nouvelle période de l'histoire du patrimoine français. Pour certains, il s'agit d'une remise en cause radicale des valeurs traditionnelles du patrimoine français et des politiques publiques, dominées par le monopole de la haute culture, et spécifiquement des beaux-arts. Pour d'autres, il s'agit au moins d'un champ de possibles qui s'ouvre pour la discipline et sa reconnaissance. La mise en perspective historique de cette décision passe par un retour sur les conditions et les limites de l'institutionnalisation du patrimoine ethnologique au cours des « années patrimoine », soit la décennie 1980. Deux enjeux se dessinent au terme de ces vingt années. Un premier, muséologique et muséographique, découle directement de la crise persistante et toujours non résolue des collections d'objets ethnologiques, de leur exposition et de leur rapport à la science. Le second tient aux rapports entre des projets d'identité territoriale, ou " territoires de projet », dont le nombre va croissant depuis la loi de 1995 et surtout 1998-2000, dans le cadre de l'aménagement du territoire national et des multiples tentatives de redécoupage décentralisateur, et l'affirmation continue d'un patrimoine in situ, inscrit dans un espace dont il tire sa légitimité et qu'il légitime à son tour. Sous ces deux points de vue, l'immatériel pose un défi dont les institutions du Ministère de la Culture et les acteurs locaux sont en train de prendre la mesure.
Ce document est protégé par la loi sur le droit d'auteur. L’utilisation des services d’Érudit (y compris la reproduction) est assujettie à sa politique d'utilisation que vous pouvez consulter en ligne.

https://apropos.erudit.org/fr/usagers/politique-dutilisation/ 


\title{
LE PATRIMOINE IMMATÉRIEL EN FranCE ENTRE RENOUVEAU MUSÉOGRAPHIQUE ET « TERRITOIRE DE PROJET »
}

\author{
Dominique Poulot \\ Université Paris I Panchéon-Sorbonne
}

Depuis la signature par la France, en 2006, des textes de l'UNESCO' la question du patrimoine culturel immatériel est devenue d'actualité. Dans le monde des musées, différents relais institutionnels s'emploient à sensibiliser les conservateurs, via ICOM France par exemple. Parallèlement, la Mission du patrimoine ethnologique a entrepris une réflexion collective sur les nouvelles catégories et le nouveau cadre d'activité du patrimoine hier encore "ethnologique $»^{2}$. Ainsi, le patrimoine immatériel semble s'inscrire à l'agenda de différentes administrations étatiques selon un processus top-down caractéristique

1. La sauvegarde du patrimoine culturel immatériel formulée par l'UNESCO dans sa convention de 2003 a été adoptée par une loi du 5 juiller 2006 (loi n 2006-791) portant approbation par la France; le décret ad hoc n²006-1402 date du 17 novembre 2006.

2. Il est d'ailleurs à noter une certaine indécision, ou confusion, entre les termes de patrimoine immatériel et de patrimoine ethnologique. Le rapport Benzaïd définissait ainsi le patrimoine ethnologique : "Le patrimoine ethnologique d'un pays comprend les modes spécifiques d'existence matérielle et d'organisation sociale des groupes qui le composent, leurs savoirs, leur représentation du monde, et, de façon générale, les éléments qui fondent l'identité de chaque groupe social et le différencient des autres " (Benzaïd 1980 : 27). Le site Internet de la Documentation française proposait en 2003 la définition suivante de la Déclaration de 2002 sur le patrimoine culturel immatériel : "Ce patrimoine, fondé sur la tradition et transmis oralement ou par imitation, dénommé patrimoine ethnologique, présente tout à la fois un caractère intangible mais également un renouvellement constant dans ses formes d'expression". 
de la tradition centralisée des organisations muséales et patrimoniales françaises. La situation est, apparemment, d'autant plus favorable qu'un certain nombre d'événements récents ont mis au premier plan le dépassement de l'opposition entre l'espace social en perpétuel devenir cher aux anthropologues et l'enclos d'objets conservés au musée cher aux spécialistes de la culture matérielle.

C'est en particulier le cas avec l'ouverture, à l'été 2006, du musée du Quai Branly ce nouvel établissement consacré aux "cultures du monde " dont le geste architectural, à en croire son responsable, Jean Nouvel, revendique une sensibilité inédite à l'immatériel. Pour Daniel Fabre, grand témoin de l'histoire de l'ethnologie française, le débat à son propos inaugure plus largement l'apparition de la référence au patrimoine immatériel dans l'espace public. En effet, les deux critiques majeures adressées à cette institution excipent de valeurs inédites pour la gestion patrimoniale à la française : "d'une part celle qui dénonce le culte exclusif de l'objet en trois dimensions au mépris de toutes les autres expressions des cultures; d'autre part celle qui souligne l'absence, dans la conception même du musée, des communautés créatrices des biens exposés" $(2006)^{3}$.

Enfin, si l'on envisage les évolutions plus générales de la société française, on notera que la notion d'économie de l'immatériel a été mise en valeur par un rapport commandé par le Ministère de l'économie et des finances, qui paraît placer l'immatériel au cœur des nouvelles ressources nationales ${ }^{4}$. Simultanément, le droit de la propriété privée a évolué récemment pour tenir compte de la propriété immatérielle, en particulier de l'image. Une jurisprudence naissante fonde le contrôle du propriétaire sur l'image de son bien sur le droit de propriété (art. 544 du Code civil). La Cour de cassation l'a notamment admis à propos

3. Le second reproche est particulièrement développé dans Sally Price qui voit dans le musée un dispositif de purification des communautés et de leurs éventuels communautarismes, au nom du principe de laïcité (2007). Le texte de Daniel Fabre accompagne la remise du rapport d'étude de Gaetano Ciarcia, 2006.

4. Arrêté du 23 avril 2007 portant création d'un service à compétence nationale dénommé "Agence du patrimoine immatériel de l'État" NOR ECOP0751395A, J.O. du 12/05/2007, n $26: 8684 / 8685$. 
de l'image d'un café (le café Gondrée qui fut un des premiers immeubles à avoir été libéré en Normandie au moment du débarquement) ${ }^{5}$.

Cet état de choses explique que, pour certains, l'épisode de la Convention signée par la France fasse figure d'événement fondateur, de rupture inaugurale dans l'histoire longue de la culture nationale. Pour Jean Guibal, directeur de l'un des grands musées d'ethnologie française, et qui fut l'auteur d'un rapport sur la crise du Musée des Arts et Traditions Populaires, il s'agit de la fin d'une limitation aux seuls biens culturels " majeurs" - entendons : artistiques et monumentaux, tels que les désigne l'histoire de l'art occidental - et de la reconnaissance de la diversité des cultures humaines. Daniel Fabre se réjouit de même d'une ratification qualifiée d' " historique » en remarquant au passage que "pour la première fois, une inflexion significative dans l'institution de la culture ne se réfère pas à l'expérience historique et à la jurisprudence occidentale, française en particulier» $(2006)^{6}$. La rupture devait venir de l'extérieur, puisqu'à l'en croire "à aucun moment de son histoire la nation française ne s'est reconnue - c'est-à-dire ne s'est incarnée - dans ses savoirs oraux tout comme elle ne s'est jamais reconnue dans ses musées d'ethnographie nationale ". Pour ces deux acteurs et témoins privilégiés de l'histoire récente du patrimoine ethnologique français, la ratification de la Convention sur le patrimoine immatériel par la France est « une décision qui rompt avec deux siècles de hiérarchisation étatique des biens de culture ». Elle rencontre assurément, aussi, une ouverture de la muséologie française aux normes et aux exigences internationales dont on peut donner maints exemples, entre qualité professionnelle, satisfaction d'un tourisme mondialisé, succès de certains architectes dont le marché est lui-même global, enfin légitimité de modèles unanimement reconnus? ${ }^{7}$ La réussite du grand Louvre ou du Musée du quai Branly mise à part, l'exemple le plus significatif, peut-être, est celui du programme de la Cité de l'immigration

5. Toutefois, la seule utilisation de l'image n'ouvre pas en soi une possibilité de contrôle. Le propriétaire doit apporter la preuve qu'il a subi un trouble dans la jouissance et l'utilisation de son bien. Cass. civ. lère, 10 mars 1999 ; voir Nathalie Mallet-Poujol et Jean-Michel Bruguière 2001: 84 .

6. http://www.lahic.cnrs.fr/spip.php?article306

7. On trouvera une comparaison possible avec l'Imperial War Museum et le musée d'Ypres dans Whitmarsh $2001: 1-15$. 
dans l'ancien $\mathrm{MAAO}^{8}$. Jacques Toubon, ancien ministre de la Culture et patron du projet, a fait le tour du monde des musées d'immigration en quête d'inspiration avec son équipe. Un colloque international sur les musées d'immigration dans le monde a été organisé à la Bibliothèque Nationale de France, enfin l'inspiration d'Ellis Island a été maintes fois évoquée?.

Cette rupture patrimoniale doit en tout cas avoir des conséquences juridiques importantes. La définition du patrimoine français est demeurée largement dominée, jusqu'ici, par la prééminence du bâti et par celle des collections nationales. Elle est, par exemple, plus restreinte que celle forgée par le Conseil de l'Europe à propos de l'héritage culturel européen, "fait des créations de la nature et de l'homme, de richesses matérielles mais aussi de valeurs morales et religieuses, de convictions et de connaissances, de peurs et d'espoirs, de visions du monde et de modes de vie dont la diversité est source de la richesse de la culture commune sur laquelle se fonde la construction européenne " (Cornu 2003 :3). Pour les juristes français, en effet, certaines activités ou pratiques telles que les coutumes, traditions, savoir-faire n'ont pas "besoin d'un encadrement juridique pour s'épanouir. En ce sens, le patrimoine au sens juridique ne recouvre qu'un sous-ensemble du patrimoine au sens large. Le législateur sélectionne un certain nombre d'éléments pour organiser leur régime de protection. Le droit français est aujourd'hui centré sur la protection des éléments matériels du patrimoine, d'où une approche bien plus restrictive" (Cornu 2003: $3)$. L'adoption de la convention internationale doit donc faire évoluer les conceptions nationales de protection du patrimoine.

L'enjeu est d'autant plus important que les exemples ne manquent pas de la réaffirmation de la définition patrimoniale la plus classique. Le premier numéro de la nouvelle revue Patrimoines de l'Institut national du patrimoine en porte témoignage. Paru en 2006, il est consacré à la

8. Issu au début des années 1990 de militants associatifs et d'historiens, le projet d'un musée de l'histoire de l'immigration est à nouveau caressé en 2001 par Lionel Jospin, Premier ministre socialiste. En 2002, le Président Jacques Chirac le prend à son compte. En avril 2003, il devient partie prenante des desseins d'une politique d'intégration sous la forme, bientôt, d'un " centre de ressources et de mémoire de l'immigration ». La Cité nationale de l'histoire de l'immigration est officiellement projetée le 8 juillet 2004 et le musée est inauguré le 10 octobre 2007 ; elle comprend un réseau de partenaires associatifs.

9. Voir Nancy L. Green (2007) pour une excellente mise en perspective à cet égard. 
question de la protection des monuments historiques. Par ailleurs, le monde des musées, à peine sorti des débats liés à l'application de la " loi musées » qui a réformé - en vérité faiblement - une définition de l'institution jusque-là régie par un texte de $1945^{10}$, a été mobilisé par des disputes exclusivement centrées sur le devenir des collections. Les polémiques ont fait rage à propos de la politique internationale (menée à l'échelon le plus élevé de l'État) touchant les prêts d'œuvres de musées nationaux à des établissements étrangers moyennant rétribution, en particulier dans le projet du Louvre d'Abou Dhabi. L'hypothèse d'une possible aliénation des collections publiques, esquissée un moment dans divers rapports, avant d'être écartée, a été un second sujet d'inquiétudes, qui a nourri ce qu'un ancien conservateur, historien d'art et pamphlétaire, Jean Clair, appelle le «malaise dans les musées ». Enfin les rivalités, pécuniaires surtout, entre le Louvre et la Réunion des musées nationaux ont régulièrement alimenté la chronique muséale et institutionnelle. Tous ces épisodes semblent ainsi réaffirmer que seules importent finalement les collections (surtout d'art), tant pour les administrations - au regard des revenus retirés de leur location - que pour l'opinion publique ou pour le monde académique.

Pourtant, les musées d'ethnologie connaissent en France des mutations rapides, marquées par une série de fermetures et de constructions, à tout le moins par des projets plus ou moins considérables - ceci après la génération des nouveaux musées d'art des décennies 1980-2000. La construction du Musée des Confluences, pluridisciplinaire, à Lyon ${ }^{11}$, celle d'un musée des arts et des civilisations de la Méditerranée à Marseille, comme le réaménagement du musée de l'Homme $^{12}$, dans la meilleure des hypothèses, doivent aboutir autour

10. Loi $n^{\circ} 2002-5$ relative aux musées de France, concernant notamment l'attribution du label «musée de France » et la création d'un Haut Conseil des musées

11. La présentation du projet sur le site internet évoque : "sept expositions de déclinaison, par exemple : conflits et exclusion, diversité culturelle et métissage, biodiversité et toutes les questions liées à la maîtrise du vivant ». Michel Côté, son directeur, a publié au cours de l'année 2008 une série d'ouvrages sur la transformation du Muséum en Musée des confluences qui constitue la meilleure présentation des enjeux du projet (La passion de la collecte : aux origines du musée des Confluences, XVII-XIXème siècles, mai, Pratiques d'exposition et Médiation et activités culturelles, septembre, Les collections, Politique et pratiques, décembre, tous édités par le département du Rhône).

12. Ceci après un premier rapport de Jean-Pierre Mohen, 2004. 
de 2012-2014, tandis que se dessine l'éventuel programme d'un grand musée d'histoire nationale en guise de nouveau grand chantier présidentiel ${ }^{13}$. Le phénomène vaut d'être noté, car la - relative émergence dans le public de l'ethnographie française vulgarisée à travers certains récits à succès des années 1960-1980, liés à la nostalgie d'un monde rural perdu (Joutard 1983) n'avait pas débouché sur un renouveau des expositions ou des musées. Il est vrai que, désormais, le musée contemporain semble moins jouer le rôle d'un instrument du travail savant que celui d'un outil de vulgarisation auprès des visiteurs (voir Le Goff 1977, 1997 ; Kavanagh 1990). Si les écomusées ont rencontré un certain public dans la période 1970-1990, les plus exigeants d'entre eux sur le plan scientifique ont fermé par la suite, ou ont abandonné leur ambition, au profit d'établissements davantage orientés vers les démarches récréatives de musées de plein-air ou assimilés. Dans tous les cas, la recherche de publics est devenue une exigence essentielle.

Dans le champ disciplinaire, Jean Jamin notait dès 1991 que "musées, collections et objets ne semblent plus guère intéresser l'anthropologie. Par une défection autant physique qu'intellectuelle de la part de la communauté professionnelle, ceux-ci sont quasiment laissés à l'abandon ou réduits à une fonction commémorative " $(1991: 113)^{14}$. La remarque, si elle vaut pour l'évolution générale de l'ethnologie, est particulièrement pertinente dans le domaine français, où les ethnologues d'après-guerre, comme tétanisés par le souvenir de Vichy, ont entretenu des relations difficiles avec leur héritage, et surtout peut-être avec ses musées. Les colloques successifs liés à la crise du Musée des Arts et Traditions Populaires ont régulièrement oscillé entre esquive de souvenirs qui fâchent et règlements de compte passionnés entre héritiers. Les expositions rétrospectives montées à l'intérieur même de divers établissements sont souvent demeurées de pieux hommages aux pères fondateurs de la grande famille de l'ethnologie française, respectueux d'une vulgate lénifiante de la tradition muséographique nationale. De ce fait, le musée a été majoritairement abordé par certains universitaires ou chercheurs sur le mode sinon du mépris, au moins de la condescendance, tandis qu'un discours non moins stéréotypé des

13. Le 16 février 2009 la ministre de la culture a confié une expertise sur les "différents sites susceptibles d'accueillir le futur Musée de l'Histoire de France " parmi lesquels Fontainebleau, l'hôtel de Soubise, les Invalides, Versailles et Vincennes. Sur ce phénomène parallèle de la muséologie française je me permets de renvoyer à D. Poulot 2008.

14. Voir aussi Jean Bazin 2002 et Johannes Fabian 2004. 
conservateurs et autres professionnels de l'établissement défendait la spécificité du métier et du lieu à l'encontre des soucis académiques. Dans ce contexte, il n'est pas sans intérêt de montrer comment une évolution apparemment terminologique - celle du patrimoine immatériel substitué au patrimoine ethnologique - mais en vérité bien plus importante engage des changements relevant à la fois d'une orientation disciplinaire et d'une volonté d'intervention politique.

\section{L'énergie du primitif et la politique folkloriste}

Sur la longue durée des XVIII"-XIX" siècles, la démarche de l'ethnologie semble se confondre avec l'inventaire d'objets empiriques, en nombre toujours croissant, susceptibles de devenir autant de matériaux d'exposition ou de muséographie. Le "paradigme des derniers ", tel qu'il est défini aujourd'hui par Daniel Fabre, est au principe d'une telle construction: l'ethnologue est alors

le dernier à pouvoir dire : telle pratique, telle croyance, tel objet ou tel savoir ont existé; telle parole a été proférée... dont nulle archive officielle ne conservera la trace. ... Du point de vue de la connaissance, la justification est toujours la même : il faut s'empresser d'aller recueillir à la source ce qui deviendra peut-être source pour les chercheurs du futur .... Mais cette option unanime a pour effet une sélection tacite et insidieuse des sujets d'étude: on penchera plutôt vers une ethnographie des œuvres, en donnant à ce dernier terme son sens le plus large. Objets de la vie quotidienne, savoirs, outils et produits du travail, habitats et sites, arts populaires, musique et littérature orale... sont toujours les premiers élus car leur description externe, leur dénombrement et donc leur capitalisation patrimoniale sont immédiatement concevables "(1986:4).

La situation change à la fin du siècle, avec l'émergence d'un discours du terrain, qui aboutit à la nouvelle fondation de la discipline, autour des écrits de Van Gennep en particulier.

En effet, comme l'a montré David L. Hoyt :

the ethnographic subject underwent a reanimation at the fin-de-siècle .... Thereafter it stood in no need of new life, coming instead fully into possession of its own. Unlike the "culture fossils ", artefacts or phantasms studied before the closing decade of the nineteenth century, a good deal of what was construed as evidence by ethnographic writers after 1890 was avowed to be alive - at least in all the various regions of "savagery ". There was, under such circumstances, no need to "restore life" to weathered ethnographic relics (2001: 333). 
L'affirmation du sujet ethnographique se joue dans la reconnaissance d'un primitif toujours actif, conjugué au présent et non pas au passé. Il ne s'agit plus de collecter les fossiles de la culture disparue, les derniers exemplaires de telle ou telle coutume ou pratique. Mieux, il s'agit d'abandonner la perspective historique et positiviste au profit d'une approche synchronique qui met fin à la thèse de survivances et porte au contraire le savant à mener des observations de terrain, sur le vif. Le primitif est approché de manière directe, spontanée, et il permet de comprendre le futur autant que le passé. Pareil basculement des repères temporels débouche sur une articulation cohérente du régionalisme et du folklore, dont l'entretien est un puissant outil politique. L'intérêt pour les dialectes et les langues locales s'inscrit dans cette perspective - ainsi chez Mistral.

Il suffit de citer Arnold Van Gennep, régulièrement tenu pour le fondateur de l'ethnologie française, pour saisir la mesure de l'écart ainsi affirmé : " ce qui intéresse le folklore, écrivait-il, c'est le fait vivant, direct; c'est si l'on veut, de la biologie sociologique, comme fait l'ethnographie. Il est très bien de recueillir dans des musées les objets en usage dans nos diverses provinces ; mais ceci n'est qu'un accessoire du folklore, sa partie morte. Ce qui nous intéresse, c'est l'emploi de ces objets par des êtres actuellement vivants, les coutumes vraiment exécutées sous nos yeux et la recherche des conditions complexes, surtout psychiques, de ces coutumes. Or, la vie sociale change sans cesse, et par suite les enquêtes folkloriques ne peuvent cesser » (1924: 46). Van Gennep refusait de la sorte d'identifier le folklore à la culture matérielle et à sa muséographie pour mettre au premier plan, comme il l'écrit en 1914, le "mécanisme de la production même, c'est-à-dire de la fabrication technique et des conditions psychiques et sociales sousjacentes dont les objets ne sont jamais que des témoins desséchés comme les plantes d'un herbier»(1914: 11).

De nombreux nationalistes définissent alors leurs programmes en ce sens, en particulier les néo-traditionnalistes du mouvement régionaliste organisé par Charles-Brun, qui critiquent la centralisation et mettent au premier plan de leurs préoccupations la défense des différences régionales, des spécificités culturelles. Les antiquaires des générations précédentes sont leurs ennemis, accusés d'avoir embaumé la culture, de n'avoir jeté qu'un regard érudit sur leurs objets d'études: ainsi les pionniers du folklore, de Mélusine ou de la Revue des traditions populaires, font-ils figure de savants inutiles au redressement français. 
Maurice Barrès condamne de même la sauvegarde des églises de France, après la séparation de l'Eglise et de l'Etat en 1905, sous la forme de musées ou de lieux culturels - sans pour autant défendre le catholicisme en tant que tel. C'est au nom de l'énergie nationale, de la force de ses paysages et de ses modes de vie que les monuments, comme les traditions, doivent être non seulement conservés à des fins d'étude ou d'archivage, mais mobilisés afin de nourrir un projet actuel. Rien n'est pire que l'embaumement des musées ou la restauration selon des procédures savantes à la Viollet-le-Duc.

Une salle de France avait été aménagée en 1884 dans le Musée d'ethnographie du Trocadéro - elle ferme en 1928. Le tournant est l'ouverture de musées régionaux, tels le Musée Basque de Bayonne, le Musée Breton de Quimper ou le Museon Arlaten d'Arles imaginé en 1898 par Frédéric Mistral à partir de l'observation quasi ethnographique de la Provence, et qui fait figure de modèle. Il est suivi en 1904, d'un Musée Dauphinois à Grenoble conçu par Hippolyte Müller pour "recréer la pensée qui a créé l'objet". Cependant, à l'inverse des "Musées de maisons" en plein air qui se multiplient au début du XX" siècle dans les Pays Scandinaves, les Pays-Bas, l'Allemagne mais aussi en Roumanie, en Grande Bretagne et aux États-Unis, la France ne connaît pas d'institution d'importance. Elle ne connaît pas non plus le détournement ultérieur de ces institutions par les divers régimes autoritaires des années 1930, qui les mobilisent à des fins de propagande idéologique, voire raciste et xénophobe. Le programme à la fois érudit et politique du folklore français débouche en 1937, parallèlement à l'installation du Musée de l'Homme, sur une première version du Musée national des arts et traditions populaires due à Georges-Henri Rivière. Le folklorisme est bien présent dans ces projets, mais ces programmes sont tôt interrompus par la déclaration de guerre. Si le principe d'une " application » de la discipline a en France une longue histoire, il a fini par disparaître de manière irrémédiable à l'issue de Vichy.

Plus largement, on peut décrire le rapport du musée à l'ethnologue sous les trois figures que Noël Barbe a repérées dans la tradition intellectuelle française, à savoir « le déploreur de l'utilité, l'expert fraternel et l'inventeur de science détaché ", respectivement identifiés à Claude Lévi-Strauss, Michel Leiris et Roger Bastide. "Où Claude Lévi-Strauss visait à installer une discipline nouvelle dans le concert des sciences sociales en justifiant de son utilité sociale, où Michel Leiris tentait de répondre aux inconforts de la pratique ethnographique dans 
la situation coloniale en la politisant, Roger Bastide vise à faire de l'anthropologie une discipline qui permette de "contrôler les forces sociales" comme l'homme a soumis "es forces de la nature", à faire d'une anthropologie appliquée le cœur de la scientificité de l'anthropologie générale» (Debaene 2006 : 54). L'invention à neuf de l'ethnologie française, après 1945, s'inscrit en marge d'abord du courant principal de l'ethnologie, puis dans un mouvement de retour sur soi de l'anthropologie, du lointain au proche: la discipline s'élabore en remplaçant en quelque sorte l'anthropologie de l'autre par celle du même. Les causes en sont complexes, qui mêlent le processus de décolonisation, la reconversion de l'anthropologie universitaire, plus tard l'élaboration d'une demande publique grâce à la Mission du Patrimoine ethnologique, qui est venue complexifier la situation entre la recherche et les musées sans jamais que ce rapport soit pleinement analysé et a fortiori réglé ${ }^{15}$. Aujourd'hui, du reste, l'importation du terme et de la démarche de "patrimoine immatériel " est souvent interprétée sur le mode d'un rapatriement supplémentaire de dispositifs mis en œuvre sur des terrains exotiques et désormais appliqués à la métropole. L'auteur d'un rapport récent sur la politique du patrimoine immatériel en France écrit qu'il a «focalisé (son) examen sur la migration du concept de patrimoine immatériel en France " grâce à une " approche comparative, entre contextes africains et européens, des usages publics du concept " (Ciarcia 1990).

\section{Une modernité millitante : les musées de société}

C'est aussi après la seconde guerre mondiale que se constitue un véritable réseau de musées professionnels régionaux et locaux sur le modèle imaginé par Rivière ${ }^{16}$. En particulier, le programme du Musée de Bretagne, ouvert en 1957 à Rennes, entend présenter " le temps et l'espace autour d'un territoire donné, les rapports de l'homme et de la nature ". Le Musée national des Arts et Traditions Populaires, quant à lui, n'ouvre que bien plus tard, entre 1972 et 1975, dans un quartier bourgeois et excentré de Paris - en bordure du Jardin d'Acclimatation

15. Voir le Schéma Directeur de la Recherche en Sciences Humaines 2005-2008 dans les musées nationaux. Deux ouvrages à caractère partiellement autobiographique sont à cet égard utiles: Martine Segalen 2005 et Jean Cuisenier 2006.

16. Né en 1897, fondateur du Musée des Arts et Traditions Populaires en France puis directeur de I'ICOM (International Council of Museums, UNESCO) de 1948 à 1966. 
- sous les auspices du structuralisme de Claude Lévi-Strauss pour l'inspiration intellectuelle (au moins proclamée) et du modernisme international corbuséen pour l'architecture (passablement ignorée) ${ }^{17}$.

Le mot écomusée apparaît en France en 1971, l'année de la création du Ministère de l'environnement, dans le cadre de la mise en place des Parcs naturels régionaux, comme un outil de connaissance de l'espace et du «projet de vie" d'une population ${ }^{18}$. Les premiers écomusées, conçus à Marquèze dans l'enceinte du Parc naturel régional des Landes de Gascogne, puis à Ouessant au sein du Parc naturel régional d'Armorique, servent de références pour élaborer la définition de ces établissements. Un écomusée réunit en principe différents sites au sein d'une région géographique et fournit à ses visiteurs le moyen de comprendre l'histoire et la géographie du lieu; il illustre les liens étroits tissés par la communauté d'habitants entre l'environnement, les ressources naturelles et la technique agricole, artisanale, manufacturière ou industrielle. L'écomusée se définit ainsi à l'opposé du musée traditionnel, " temple de la culture " réservé à l'élite qui met l'accent sur une collection d'objets et son bâtiment : il se caractérise a contrario par un territoire, son paysage et ses hommes. Les décisions de créer des parcs naturels régionaux et le cas échéant conjointement des écomusées sont le fait de responsables politiques, d'associations et de scientifiques qui entendent mobiliser les habitants au service de la protection de territoires naturellement et culturellement homogènes. En 1976 Georges-Henri Rivière précise sa définition, inlassablement reprise depuis par tous les militants de cette nouvelle muséologie. L'accent est désormais mis sur la population :

C'est un miroir où cette population se regarde, pour s'y reconnaître, où elle cherche l'explication du territoire auquel elle est attachée,

17. Jean Dubuisson est un grand représentant de l'architecture française des Trente Glorieuses. Cf. Jean Dubuisson, 2008.

18. La première définition de l'écomusée, proposée par Georges-Henri Rivière, est adoptée en 1971 lors de la Neuvième conférence du Conseil International des Musées, en ces termes : "l'écomusée est un musée éclaté, interdisciplinaire, démontrant l'homme dans le temps et dans l'espace, dans son environnement naturel et culturel, invitant la totalité d'une population à participer à son propre développement par divers moyens d'expression basés essentiellement sur la réalité des sites, des édifices, des objets, choses réelles plus parlantes que les mots ou les images qui envahissent notre vie". 
jointe à celle des populations qui l'y ont précédée, dans la discontinuité ou la continuité des générations. Un miroir que cette population tend à ses hôtes, pour s'en faire mieux comprendre, dans le respect de son travail, de ses comportements, de son intimité ${ }^{19}$.

Musée de l'homme et de la nature, l'écomusée veut illustrer autant la société traditionnelle que la société industrielle, remonter en deçà du temps où l'homme est apparu, s'étager à travers les temps préhistoriques et historiques qu'il a vécus, déboucher sur le futur sans en principe se poser en décideur, mais pour « jouer un rôle d'information et d'analyse critique ". L'écomusée idéal revendique la double qualité de conservatoire du patrimoine naturel et culturel des populations concernées et de laboratoire puisqu'il est à la fois matière à études théoriques et pratiques, et acteur de ces études. Concrètement, il s'agit souvent d'un ensemble de petits musées locaux constitués en réseau, aidant les populations locales à prendre conscience d'un patrimoine, et animés par des personnels au statut souvent flottant, entre bénévolat et professionnalisme - parfois au nom de l'autogestion. Isaac Chiva, revenant en 1990 sur les vingt années précédentes, juge que «la société française réagit, dans des circonstances de crise, par un mouvement de retour vers le passé, par une aspiration à la nature, enfin par un regroupement sous la bannière du local "sur lequel les ethnologues doivent s'interroger. Quelques années plus tard, Christian Bromberger reconnaît que la décennie 1980 a connu " une situation prolifique en projets fébriles ou plus assagis - et que c'est sans doute pour y apporter une réponse institutionnelle qu'apparaissent concepts et administrations du patrimoine ethnologique, qui tendront à coordonner, orienter, maîtriser ce pullulement créatif et erratique " (Bromberger 1996: 1618).

En d'autres termes, la première génération d'écomusées est issue d'une demande sociale - ou du moins s'en réclame, car elle est généralement le fruit de l'activisme d'élus ou d'animateurs passionnés qui ont su trouver les voies d'une reconnaissance collective. Les exemples les plus célèbres de ces écomusées sont ceux de la Communauté urbaine du Creusot Montceau-les-Mines, de Fourmies-Trélon, du NordDauphiné (aujourd'hui disparu), de la ville nouvelle de Saint-Quentinen-Yvelines. Ils ont connu, au cours des dernières décennies, des réaménagements importants, souvent pour devenir de "vrais » musées,

19. Définition de Georges-Henri Rivière le 13 janvier 197, cf. "Définition évolutive de l'écomusée », 1985: 142. 
ou pour contribuer à un développement touristique qui n'était pas leur but premier. D'autres ont fermé. Enfin beaucoup des écomusées ultérieurs sont nés de l'envie de conserver les vestiges d'une activité, technique ou non, liée à l'histoire locale, et relèvent de la catégorie de musées de plein air ou de musées de site. Hugues de Varine, l'un des pères de cette nouvelle muséologie de la décennie 1970, et en particulier du Creusot ${ }^{20}$, dira plus tard :

What I do feel able to claim to have invented, however, is the name " eco-museum ", a general-purpose word which was intended to cover all types and sizes of community museums, in both town and rural areas. The fact that the word has been so often misused is not my fault. There are those, for example, who fail to discinguish between an eco. museum and an open-air museum, ignoring the fact that a true ecomuseum, like a true community museum, is essentially and at its best a museum which contains and reflects a double input, an input from the community itself and an input from outside advisers ${ }^{21}$.

Si ces musées correspondent bien à une demande, celle-ci s'alimente de ressources plus évidentes en matière de médiation que dans les musées classiques. En particulier, ces établissements peuvent recourir au témoignage oral, représenté in vivo ou archivé, des acteurs, ce qui rend leur abord plus facile au moins en apparence. Leur public y est prioritairement familial : quelque $51 \%$ des visiteurs dans les enquêtes récentes (depuis 2002) sont fréquemment accompagnés de jeunes de moins de 15 ans. La fréquentation est très variable selon l'implantation de la structure mais l'Observatoire permanent des publics de la Direction des musées de France l'estime pour les musées de terroir ou de technique de 10000 à 20000 visiteurs par an (entre 1000 et 370000 pour la centaine d'établissements étudiés dans l'échantillon). Les Français considèrent dans leur grande majorité $(95 \%$ selon un sondage IPSOS réalisé en 2001) qu'il est important de " préserver et de mettre en valeur le patrimoine rural, afin d'assurer la transmission d'une identité aux générations futures, de préserver un cadre de vie commun et d'aider au développement d'activités économiques, sociales ou culturelles des différents territoires ». Les attentes sont aussi fortes en termes d'émotions et de sensations, de présentation et d'esthétique dans la mise en scène

20. Hugues De Varine a été directeur de l' ICOM de 1964 à 1974.

21. Dans une conférence prononcée le 15 October 1993, devant l'Université d'Utrecht, "Tomorrow's Community Museums ", à l'occasion du prix du musée européen de l'année. 
des contenus, qu'en termes de services offerts au visiteur (la boutique ou le café doit offrir des produits représentatifs des collections ou du patrimoine immatériel représenté).

Enfin la catégorie des "Musées de société » est forgée au sein de la Direction des Musées de France en 1991, pour regrouper, au-delà des querelles typologiques ou générationnelles, les musées d'ethnologie et ceux d'arts et traditions populaires, les musées techniques et industriels, les musées d'histoire, ceux de site et de plein air, les musées maritimes et enfin les écomusées. Le point commun de ces musées est d'être attachés à un territoire dont ils valorisent l'ensemble des expressions culturelles et dont ils offrent une lecture à leurs publics. Leur muséographie connaît également des similitudes avec, au-delà de la classique exposition d'objets et de documents, le recours à diverses médiations (audiovisuels, manipulations...) et l'appel à une participation plus ou moins évidente des habitants de la communauté patrimoniale. Un grand nombre de musées de sociétés entendent illustrer l'environnement d'une communauté autant que sa culture : consacrés à "l'esprit d'un lieu " dans ce qui le caractérise et lui confère son originalité profonde, ils composent un tableau où se révèlent un territoire et son paysage, une communauté et ses modes de vie. Reprenant le discours d'un risque d'uniformisation et de banalisation des cultures locales dans un monde de plus en plus globalisé, ils participent de l'exaltation du particulier en rappelant volontiers le temps où les formes de mise en valeur s'accordaient pour l'essentiel avec les ressources du milieu. Il s'agit à la fois d'évoquer - de regretter souvent - un développement qui respectait l'environnement et de prôner le respect de valeurs humaines - convivialité et solidarité - volontiers identifiées à la vie de petites communautés rurales ou semi-rurales de l'époque préindustrielle. Dans cette logique, la muséologie mise en œuvre repose sur quatre dimensions : la recherche de l'authenticité - du «vrai »dans sa dimension humaine et matérielle; la passion de la particularité, incluant le curieux et le rare; le culte de la patine ou de l'épaisseur historique; l'attention enfin au détail qui fonctionne comme un révélateur de la société disparue ou submergée par la modernité.

Les territoires de l'écomusée sont alors formés de lieux disjoints choisis pour leur exemplarité paysagère et architecturale : les bâtiments incarnent les différents activités des hommes (ou les différentes époques de leur activité principale). À la Grande Lande, dans le Parc naturel régional des Landes, le lieu central est une clairière dans la pinède qui abrite un airial, celui de Marquèze, bâtiment d'exploitation et lieu de 
vie de la cellule de base du monde forestier au XIX ${ }^{\mathrm{e}}$ siècle; s'y ajoutent des constructions disséminées dans la forêt, des ruches et des parcelles cultivées. Dans le Parc naturel régional d'Armorique, l'écomusée est formé de quinze lieux mis en réseau : certains évoquent les différents paysages des Monts d'Arrée, depuis les hauteurs ( $382 \mathrm{~m}$ ) jusqu'aux rias en bordure de mer, en passant par les cuvettes tourbeuses; d'autres exposent les espèces animales du territoire (avec un écomusée du loup) ou encore les activités passées et présentes (moulins à vent et à eau, tanneries, fermes...).

La plupart de ces musées sont construits autour d'une ou de plusieurs activités en voie de disparition et célèbrent de ce fait un passé perdu. Ils se font les témoins de l'intégralité d'un territoire et illustrent tant la ruralité que l'industrie d'antan si bien que la période mise en scène ne cesse de s'allonger, puisant désormais ses racines dans le premier XVIII ${ }^{e}$ pour s'achever dans la dernière moitié du XXe. Tous mettent en scène les outils et les techniques traditionnels, grâce à des objets et à des documents souvent prêtés ou donnés par des particuliers vivant dans le parc; ils invitent des anciens artisans pour donner des explications aux visiteurs, voire accomplir diverses démonstrations. Car "l'immersion dans les pratiques du passé, loin d'être nostalgique, éveille aux problèmes du présent" ainsi que l'affirme la brochure de la Fédération des Ecomusées en 1990. L'écomusée élabore une nouvelle représentation du patrimoine conçue comme prise de conscience d'elle-même par la société, grâce à la mise au jour (interminable) de ses "propriétés "22. Il participe en ce sens d'une dynamique inédite du «patrimoine " dans la société, dont témoignent les recherches simultanément commanditées par la Mission du Patrimoine sur les pratiques et les politiques culturelles de l'identité. Si le musée d'histoire classique mobilisait le passé pour l'avenir, l'écomusée, lui, figure plutôt, selon une excellente formule de Freddy Raphaël, " une provocation de la mémoire» (Herberich-Marx 1987). L'utopie des écomusées Rivière des années 1970 a ainsi tenté de donner une position d'acteurs aux visiteurs - même si, comme l'a montré par la suite la recherche de l'anthropologue Octave Debary à propos du Creusot, elle reposait sur l'échec d'un travail de mémoire, ou au moins sur son inachèvement.

En tout cas, ce renouveau muséal s'est structuré autour de l'opposition entre immatériel et muséal, entre nouveauté du mouvement

22. Voir le manifeste de Terrain, la revue de la Mission du Patrimoine erhnologique du Ministère de la Culture, Fleury 1988. Un bilan de cette ethnologie est fourni par Segalen 1989. 
et conservatisme des institutions. C'est à un véritable combat entre valeurs antagonistes que l'élaboration de ces musées a d'abord donné lieu. Et cette opposition initiale s'est trouvée redoublée quelques décennies plus tard par une polémique sur le coût et l'avenir de ces musées, rapportés à ceux des musées d'art traditionnels. L'Inspecteur général des musées Édouard Pommier donnait en 1991 un article militant contre l'abus de musées de société, auquel répondaient les champions de la muséologie ethnologique et anthropologique. L'affrontement prenait la mesure de la prolifération soudaine des musées ethnographiques: parti d'une quarantaine au cours des années 1950 . 1960 , leur nombre a été multiplié au point d'atteindre environ 800 musées créés ou réinventés autour de la notion d'identité. Depuis, les collections ethnographiques au sens large représentent entre le quart et le cinquième du nombre total d'établissements: l'âpreté des débats politico-administratifs est liée à ce qui était perçu comme une soudaine concurrence par des institutions traditionnelles, elles-mêmes en plein essor ou en voie de renouvellement ${ }^{23}$.

Presque une génération après l'amertume du fondateur du Creusot est sensible

We soon fell foul of the traditional museum world and its centralised authority in Paris. We were made aware that we were breaking all the rules and that we should have to be excommunicated. The regulations, sanctified by the passage of time, laid down, among other things, that museums must have collections, and they must have visitors, a public. But Le Creusot had no collections, no mass of objects which had been entrusted to the museum for safe keeping, and it had no public. The public, that is, the community, was the museum and the museum was the public. No clear line could be drawn between the two, nor was it our intention to do so. The whole point of the eco-museum, as we conceived it, was that there was no division between the two. Our offence, and the reason for our excommunication, appeared to be rooted in the fact that museums were officially controlled by a powerful network of priests and bishops, with an accepted theology to justify their status and the structure of the organisation they controlled. We at Le Creusot had decided to establish a new kind of non-conformist, democratic museum-church, in which the congregation was the church and vice-versa. We fought a long and

23. Il faut ajouter au tableau la question des musées de mémoire de la seconde guerre mondiale, à renouveler ou à fermer: l'évolution des musées d'histoire illustre, au-delà de difficultés spécifiques, le tournant du professionnalisme que les musées de société ont dû prendre ensuite. 
hard battle over this and its effects have been felt all over the museum world ${ }^{24}$.

Au total, rarement sans doute l'opposition entre patrimoine immatériel et patrimoine matériel aura-t-elle suscité autant de passions, sinon de haines recuites, au sein du monde des musées. Il est impossible de comprendre la situation présente, et les obstacles qu'elle ménage éventuellement à l'adoption d'une politique culturelle de patrimoine immatériel, si l'on ne saisit pas le poids de cette logique institutionnelle ${ }^{25}$. L'administration parisienne n'a jamais vraiment compris ou accepté les enjeux décisifs de la génération 1970-1990 en matière de musées nouveaux : la réponse institutionnelle est restée largement figée sur l'a priori de collections matérielles prestigieuses, que l'on arrachait à leurs destinations pour les placer au musée. À l'inverse, tous les nouveaux établissements ne juraient que par l'in situ, par le quotidien et le banal de leurs objets, par l'implication de communautés de projets (même si cette dernière était surtout rhétorique).

\section{L'enjeu de l'inventaire du patrimoine immatériel}

L'approche du patrimoine immatériel au musée exige d'abord de régler la question (sociographique, sinon sociologique) de la représentativité des artefacts et des enregistrements conservés et exposés par rapport à l'ensemble des acteurs et des manifestations de ce patrimoine. En ce qui concerne l'inventaire et le classement du patrimoine immatériel, la Direction de l'Architecture et du Patrimoine (DAPA) ne dispose pas de tradition ou de savoir-faire particuliers, mis à part l'acquis de la Mission du patrimoine ethnologique, devenue Mission à l'ethnologie. Le décret de 2006 stipule que la mission ethnologie a pour but

[l] étude et [la] promotion, avec les autres instances compétentes, des divers aspects du patrimoine matériel et immatériel auxquels l'ethnologie s'intéresse à travers le territoire national ou qui touchent

24. Hugues de Varine 1993.

25. M. Nicolas Perruchot, rapporteur spécial de la commission des finances devait déclarer lors de la Séance de l'assemblée nationale du mardi 30 octobre 2007 : "Faute de temps, je ne puis poser toutes les questions qui me préoccupent, en particulier celles qui ont trait aux crédits destinés à l'entretien des monuments historiques, au bilan de la loi mécénat et à la promotion de la notion de patrimoine immatériel " (Compte rendu analytique officiel. Commission des affaires culcurelles, familiales et sociales). 
les domaines d'action de la direction, notamment les territoires et l'architecture.

La première mission, fondée sur un rapport, L'ethnologie de la France. Besoins et projets, présenté par Redjem Benzaïd, inspecteur général des Finances en 1979, envisageait de facto tous les objets de la convention UNESCO : ses appels d'offre, dès les années 1980, entreprenaient de les étudier de manière régulière, avant d'en publier les résultats ${ }^{26}$, notamment dans la revue Terrain, dont le titre emblématique avait valeur de refus idéologique, au risque de paraître manquer d'ambition - l'historien Jean-Pierre Rioux y voyait alors une platitude (voir Gerson 2003). Le tout entrait dans l'esprit d'enquêter sur l'identité en général, et sur sa transmission, mais sans souci d'inventaire ni de conservation (Grenet 2006). Il s'agissait de conduire des recherches sur des manifestations et des expressions culturelles ressenties localement comme des marques de l'identité collective. Au cours de la décennie 1980 deux représentants éminents de l'anthropologie française insistaient ainsi sur l'impératif de faire en sorte que les objets étudiés (fêtes, pratiques, manifestations...) ne soient "plus traités comme des survivances de faits anciens qui se seraient abâtardis, mais au contraire comme l'expression contemporaine de représentations conflictuelles des identités ... et des groupes sociaux qui l'investissent " (Cuisenier et Ségalen 1986: 87). La tâche du centre de recherches lié au CNRS qu'abritait le musée des ATP s'inscrivait dans cette perspective : analyser moins l'objet de musée comme patrimoine que lire sa patrimonialisation, en le reconnaissant pour signe ou symbole au sein de différents groupes sociaux, qui le font exister comme patrimoine, en exerçant des choix stratégiques ${ }^{27}$.

26. La Mission du Patrimoine ethnologique a une importante activité éditoriale, avec Terrain, semestriel lancé en 1983, et la collection "Ethnologie de la France » initiée l'année suivante sous forme de deux séries, "Les ouvrages », et les "Cahiers", et le Répertoire de l'ethnologie de la France, annuaire de 1990 qui recense aujourd'hui en ligne 700 chercheurs et spécialistes et 950 organismes tels que centres de recherche, musées, associations (http://www.culture.fr/ documentation/repethno/pres.htm).

27. Le Rapport Colardelle le rappelait en ces termes: "Trois dimensions centrales constituent la spécificité de ce laboratoire : une réflexion sur la mémoire et la patrimonialisation : quel est le rôle d'un musée de société tant à l'égard de l'histoire qu'à celui de la mémoire, en particulier de la mise en mémoire du contemporain; une réflexion sur le sens de l'objet, et sur le rapport - tant pratique que symbolique - aux objets de la vie quotidienne; une interrogation sur le rôle des chercheurs dans un musée : rôle critique, rôle de médiateur entre le discours des acteurs sociaux et le discours muséal. " 
Dès lors, les musées peuvent être tentés d'intervenir activement à leur tour dans la mise au jour de tels processus. Une de ces expériences a été conduite en 2003, au musée d'archéologie du Jura, à Lons-leSaunier, à l'occasion de l'exposition «Patrimoines singuliers - Chacun son patrimoine. Inventaire intime des Jurassiens du début du XXI ${ }^{\mathrm{c}}$ siècle». Tenue entre le 5 avril et le 30 novembre 2003, elle débute par un appel du musée par voie de presse, courrier et sollicitations diverses. Ces appels, matérialisés sur des feuilles jaunes, sont composés de deux parties. La première est un texte de la conservatrice du musée - titré "La prochaine exposition du Musée sera... la vôtre ! " - qui écrit : " Cette exposition sera constituée d'une collection composée de la ou des réponses que chacun souhaitera apporter à la question suivante: "qu'est ce qui, pour vous, évoque le patrimoine ou la mémoire ?". Chacun est appelé à prêter, pour une exposition temporaire, un objet quel qu'il soit, qui renvoie à " son image du patrimoine ». "Dire le patrimoine et la mémoire " figure le but à atteindre. Pareilles tentatives d'une coproduction de l'exposition avaient eu lieu auparavant dans des musées d'histoire : ainsi au lancement du musée de Péronne, pour recueillir les traces locales du premier conflit mondial. En 1987 l'Historial organisa un mouvement appelé «Faites entrer votre nom au musée ", pour collecter les objets: d'une part les noms des donateurs seraient consignés dans les activités de l'Historial, d'autre part les objets recueillis deviendraient " une part inaliénable du patrimoine historique national " (Le Courrier Picard 1987)28. Ceci est à mettre en rapport avec diverses initiatives très médiatiques à propos de "parole des poilus " (France Inter) - un processus de collecte de témoignages contemporain du déploiement d'une littérature érudite sur le sujet. Si l'éparpillement de telles initiatives est la règle, il n'en reste pas moins que PORTETHNO, le répertoire des recherches et ressources en ethnologie de la France qui informe sur des actions et des initiatives touchant le patrimoine matériel et immatériel auquel s'intéresse l'ethnologie, présente une sélection d'organismes (centres de recherches, associations, musées, écomusées et musées de société, ethnopôles, parcs naturels régionaux, bibliothèques, centres d'archives, sociétés savantes, etc.) associés à de telles actions patrimoniales. On y trouve surtout une analyse des principales ressources documentaires (littérature grise et imprimés, fonds sonores, documents audiovisuels, iconographie, fonds

28. Sur la question des objets et de leurs mémoires on se reportera aux études réunies par Octave Debary et Laurier Turgeon 2007. 
et collections d'ethnographes) qui ont partie liée avec une activité de conservation ${ }^{29}$.

La situation particulière de l'ethnologie de la France explique que l'un des débats constants, ces dernières années, ait porté sur l'opposition, ou à tout le moins la relation ambiguë entre ethnologie appliquée, dite pour ses adversaires "de gouvernement ", et science désintéressée. Elle explique aussi que ce débat ait essentiellement mobilisé la réflexion d'ethnologues professionnels naguère conseillers pour l'ethnologie au sein des Directions Régionales des Affaires Culturelles (DRAC), en relation directe avec les Directions du Ministère et avec la Mission du patrimoine ethnologique, et devenus ensuite ethnologues " académiques", collègues de laboratoire d'autres ethnologues demeurés de purs "chercheurs". Ainsi, c'est à l'occasion de la publication d'un ouvrage sur le patrimoine rural que des tenants de la sociologie "critique" dirigèrent leurs attaques contre le Ministère de la Culture, suscitant des réponses argumentées ici et là ${ }^{30}$. Pour beaucoup d'observateurs, du point de vue institutionnel, la Convention donne enfin la possibilité à cette administration d'aller au bout de sa logique, et de calquer son fonctionnement sur celui des Directions antérieures, plus prestigieuses et mieux dotées. Daniel Fabre juge ainsi que le Conseil du Patrimoine Ethnologique du Ministère de la Culture, créé en 1980, avait dès l'origine pour souci de s'occuper des biens "immatériels" caractérisant les modes de vie, de pensée et de savoir.

Cette immatérialité était alors décisive, elle justifiait la localisation de la Mission auprès de la Direction du Patrimoine, les biens en trois ou deux dimensions restant l'apanage principal des Musées. Cependant, le Conseil rassemblait en son sein tous les acteurs de la chaîne patrimoniale dont les différentes directions du ministère

29. http://www.culture.gouv.fr/mpe/portethno/

30. Le dossier réunit l'attaque de Gilles Laferté et de Nicolas Renahy, "Campagnes de tous nos désirs"... d'ethnologues » dans L'Homme, 166, 2003, dont la réponse des auteurs de l'ouvrage incriminé, André Micoud, Laurence Bérard, Philippe Marchenay et Michel Rautenberg, et la réplique "L'ethnologue face aux usages sociaux de l'ethnologie ". À côté de la polémique elle-même on signalera les analyses de Jean-Louis Tornatore (2007). Pour lui, le débat sur la distinction implication/application, " retrouvée ", en pratique, par les " ethnologues" de la Mission, n'a pas été connecté à une réflexion féconde sur les rapports de l'anthropologie avec les peuples colonisés, avec les États (des continents traditionnels de l'anthropologie) et les organisations non gouvernementales. Il manque à l'ethnologie impliquée "à la française " d'avoir été mesurée à la notion d'implication, au sens d'anthropological advocacy (voir Bruce Albert $1995: 87-118)$. 
intéressées à la musique, la danse, le spectacle vivant, les archives... et bien évidemment les musées $(2006)^{31}$.

Finalement, la signature de la Convention jouerait exactement, pour le patrimoine immatériel, le rôle qu'a joué l'adoption d'une loi pour la conservation des monuments - cette loi que Mérimée réclamait à cor et à cri pour garantir sa politique d'intervention. En quelque sorte, la signature de la Convention signerait, avec l'entrée au port du patrimoine ethnologique, une normalisation des pratiques françaises en la matière après un long retard - sous la forme d'une adoption de la modernité internationale.

\section{Un défl muséologique et muséographique}

La réussite de la greffe éventuelle du patrimoine immatériel sur les musées français tient à la capacité, intellectuelle et matérielle, de ces établissements à traiter ce projet et à s'en saisir sous forme d' "objets " collectés. Or le paradoxe de la conservation immatérielle peut conduire les conservateurs à rabattre leur lecture sur l'affect ou sur l'esthétique comme seul mode d'appréhension. Est ici en jeu, en d'autres termes, la possibilité d'une muséographie et d'une muséologie propre à se saisir de l'immatériel et à le mettre en scène. Elle suppose une articulation entre l'Inventaire et les musées qui se cherche à travers quelques tentatives ${ }^{32}$.

31. Rappelons qu'en 1980 ont été créés deux organismes distincts, à l'échelon ministériel, le Conseil du patrimoine ethnologique et la Mission du Patrimoineethnologique. Tous deux relèvent de la Direction de l'architecture et du patrimoine, qui a pour mission de "recenser, étudier, protéger, conserver et faire connaître le patrimoine archéologique, architectural, urbain, ethnologique, photographique et les richesses artistiques de la France». Le Conseil du patrimoine ethnologique, formé pour quatre ans de délégués de l'administration et d'experts, est "l'instance scientifique qui définit, au sein du ministère chargé de la Culture, les orientations d'une politique nationale de l'ethnologie de la France ». La Mission du Patrimoine echnologique est son organe d'exécution. Elle est composée d'un groupe de fonctionnaires centraux et d' « ethnologues régionaux " ou de "conseillers à l'ethnologie " en principe au nombre de quatorze, appartenant aux Directions régionales des Affaires culturelles.

32. L'Institut national du patrimoine (INP) a organisé une journée d'études : «Le patrimoine culturel immatériel de l'Europe. Inventer son inventaire", le vendredi 30 novembre 2007, qui a été l'occasion de faire appel aux témoignages d'inventaires étrangers, en particulier l'entreprise québécoise conçue par Laurier Turgeon, et de mettre au premier plan la maison des cultures du monde pour son antériorité d'opérateur français en matière de spectacle vivant en particulier. 
Mais la tragi-comédie du musée national des arts et traditions populaires figure plutôt, aujourd'hui, un échec annoncé.

Le musée imaginé par Georges-Henri Rivière présentait une vue éternelle des traditions françaises dans un rapport d'empathie, sinon de connivence, avec le public, malgré ses protestations d'ascétisme scientifique et esthétique. La décision de supprimer le MNATP a été prise en 1998 par Catherine Trautmann, alors ministre de la Culture, et confirmée par Jean-Jacques Aillagon: il a fermé à l'automne 2005. Michel Colardelle, arrivé à sa tête en 1996, avait prévu un nouvel établissement pour le remplacer à Marseille, qui devait considérer les objets, à l'inverse, comme profondément inscrits dans l'histoire. En 2001, il avait décidé l'élargissement de son territoire géographique et l'extension de son propos - " civilisation " et non seulement " culture populaire " - (Colardelle 2001). La plaquette du futur musée résumait en ces termes le projet:

Face aux puissants mouvements de replis identitaires et communautaires qui caractérisent le monde contemporain, il est indispensable de créer des lieux de rencontre et d'ouverture. Face aux murs qui se dressent, aux incompréhensions qui s'accumulent et aux rejets qui se préparent, il est indispensable de rétablir des ponts entre les cultures d'Europe et de la Méditerranée .... La création du MuCEM traduit la volonté de relier plutôt que de s'enfermer, de choisir l'échange et le partage plutôt que le refus de l'autre, de créer à Marseille un grand lieu de rencontre et de médiation entre les cultures ${ }^{33}$.

Le Musée des Civilisations de l'Europe et de la Méditerranée (MuCEM) s'intéressait donc aux civilisations de l'Europe et de la Méditerranée, du Moyen Âge à l'époque contemporaine, en s'appuyant sur l'ensemble des sciences sociales, l'etnnologie restant la discipline centrale. Le programme muséographique se réglait sur un questionnement décliné en cinq thèmes, eux-mêmes à renouveler tous les cinq ans: "Le paradis", "L'eau», "La cité», "Le chemin" et "Masculin et Féminin». En attendant sa réalisation définitive, le MuCEM a réalisé une série d'expositions temporaires qui définissaient sa campagne de collecte et son ambition. Une salle dite "Atelier de l'ethnologue » entendait montrer le travail de l'ethnologue tel qu'il est conf̧u dans les musées de société. Il s'agissait d'introduire le visiteur à

33. Plaquette du futur musée, sans lieu ni date. 
l'histoire de l'ethnologie à travers l'exemple du musée, en rendant compte de la pratique quotidienne de l'ethnologue, de sa collecte des informations, à travers des interviews d'ethnologues et des films ethnologiques. Le nouveau musée voulait apparaître de la sorte l'héritier de la tradition des ATP, telle qu'elle se donne encore à lire aujourd'hui dans les établissements installés en région et qui continuent leur travail. Mais cette déclaration d'intention n'a jamais convaincu ses adversaires, tant au sein du monde politique, en particulier marseillais, qu'au sein du monde de l'ethnologie, en raison de son ambition de couvrir une aire géographique problématique par rapport à ses collections et à ses possibilités réelles de faire sens pour les visiteurs ${ }^{34}$. Au cours de l'année 2008, Stéphane Martin, président du musée du Quai Branly, a reçu la mission de conduire une réflexion sur le concept scientifique et culturel de la nouvelle institution. Enfin le 13 janvier 2009, le Président de la République, dans le cadre du projet de l'Union pour la Méditerranée, a annoncé la création à Marseille d'un grand musée " consacré aux cultures des peuples de la Méditerranée » - qui devra coïncider avec Marseille capitale de la culture européenne en 2013. D'après le discours de la ministre de la culture Christine Albanel à Marseille le 22 janvier suivant, " cet établissement dépassera les strictes limites d'un musée de société traditionnel et fonctionnera comme une cité à double vocation, nationale et internationale, consacrée à questionner, au travers d'une politique culturelle et scientifique favorisant la multidisciplinarité, les relations qui unissent l'Europe aux pays méditerranéens. Il sera doté de deux pôles, l'un consacré aux expositions, aux débats, l'autre à la conservation des collections, à l'étude et la pédagogie ». En d'autres termes le musée nouveau s'oriente désormais vers un profil de "Cité ", selon un concept désormais rodé dans le monde des musées, et revêt un caractère artistique également d'actualité depuis l'ouverture de Branly. La décision, tardive, sanctionne l'abandon progressif du MuCEM par ses anciens appuis au sein de l'ethnologie savante française comme l'épuisement d'une équipe au long d'une dizaine d'années

34. Cf. l'assemblée générale du personnel du MNATP-MuCEM, tenue le jeudi 29 mai 2008, et le courrier envoyé le 6 février 2009 à Christine Albanel par les syndicats du ministère à propos du devenir du MNATP à propos du « sort d'un musée national fort maltraité ces dernières années". 
d'atermoiements budgetaires et politiques, malgré d'indéniables réussites ${ }^{35}$.

Cette apparente impossibilité d'un musée national critique de l'athropologie contemporaine n'est pas sans évoquer le diagnostic récemment porté par Anthony Shelton (Butler 2007) sur l'évolution mondiale des musées d'ethnographie. L'un de ses traits marquants serait, à l'en croire, le partage entre une muséologie de collaboration avec les communautés, dans les grands établissements de capitales, qui, bien qu'elle soit basée a priori sur une réflexion analytique, attend toujours en fait une clarification de ses positions épistémologiques (ce serait l'un des paradoxes du succès du Musée du Quai Branly) ${ }^{36}$ et une muséologie critique enracinée pour sa part dans quelques établissements de taille moyenne, liés à des universités, et situés à la périphérie géopolitique des premiers (musées de Neufchâtel, de Göteborg, de Coïmbra, UBC museum). L'une des explications possibles de l'échec du MuCEM serait donc que la réorganisation d'une institution ancienne, prestigieuse et centrale, comme le Musée national des ATP de Paris, ne peut prendre la forme d'un musée académique de région : comme l'écrit Christian Bromberger :

le MuCEM brouille les frontières et ne correspond à aucune entité politique établie: ni Marseille, ni la Provence, ni la France, ni l'Europe. Le projet ne prétend pas, dans ses meilleurs attendus, présenter successivement des aires culturelles, mais ..., plutôt que de conforter des identités, de déranger en donnant à penser des convergences, des parentés et des différences. Un tel établissement où il ne serait question ni de soi ni des autres mais de soi et des autres, de leurs affinités, de leurs frictions, de leurs conflits ne se plie pas aux dimensions habituelles d'un musée et peut susciter l'inquiétude (2007: 417).

35. Voir ainsi le propos faussement détaché de Christian Bromberger, membre du conseil scientifique du MuCEM, à propos de son projet scientifique : «il n'est pas sûr qu'au stade où nous en sommes la configuration choisie soit la plus pertinente et la plus convaincante " (2007: 407). "Fallait-il envisager la délocalisation et la transformation du MNATP en termes de continuité ou de rupture? L'aire couverte par le musée devait-elle être aussi vaste et s'étendre de la Scandinavie au Sahara, du Portugal à l'Iran et à la Russie ? Si la conservation des collections du MNATP est une priorité nationale, celles-ci doivent-elles occuper une place prééminente dans le futur musée centré sur le présent, sans négliger son arrière-plan historique, et sur un espace qui déborde de loin la France rurale? Sans doute fallait-il envisager deux sites, à la mesure de deux projets distincts, chacun marqué par leur temps" (420).

36. "What can an anthropologist answer to a minority population visitor who retorts with resounding support against criticism made in his name?" (Butler 2007: 2). 
En revanche, un musée "périphérique " et intimement lié à la recherche comme, à Grenoble, le musée dauphinois n'a pas cessé d'explorer les ressources de l'ethnologie régionale pour inventer de nouvelles formes d'exposition et tenir un discours "politique ", au sein de la cité, avec les communautés locales, leurs pratiques et leurs habitudes. D'après son conservateur, Jean-Claude Duclos, le musée de patrimoine régional ne peut prétendre remplir pleinement ses missions s'il limite son domaine d'intervention aux seules périodes historiques et aux seules cultures d'origines. Dans ce dessein, l'institution a conçu et réalisé depuis 1989 une série d'expositions évoquant la mémoire des communautés qui composent la population iséroise avec par exemple: L'Italie des Pouilles (Corato - Grenoble en 1989), la Grèce (Des Grecs en 1993), l'Arménie (D'Isère et d'Arménie en 1997) et la communauté maghrébine en 2000, (D'Isère et du Maghreb, Pour que la vie continue...). Ce cycle sur les identités transplantées dans le Dauphiné a pour objectif de constituer la mémoire collective, de contribuer à l'apprentissage de la différence, du respect des cultures et du partage d'une même identité, fut-elle composite. Ces expositions ont été la première manifestation de quelque ampleur d'une reconnaissance des communautés - voire de l'histoire de l'immigration en général — dans les musées français ${ }^{37}$. La muséographie employée - à savoir la présentation de personnages qui apparaissent comme autant de porteparole de leurs différentes communautés - évoque le modèle nordaméricain des histoires de vies ou des témoignages scénarisés par l'équipe muséographique pour communiquer aux visiteurs une vue "participative". Elle n'est pas, de ce point de vue, sans danger, mais elle affronte au moins une des questions cruciales que pose l'immatériel au musée, celle de l'exposition du témoignage (Idjéraoui et Davallon 2002).

L'actualité est marquée en effet par la multiplication de muséesmémoriaux, qui vont de l'histoire coloniale de l'Afrique du Nord aux mémoriaux de sites, aux mémoriaux de victimes et aux musées de la paix $^{38}$. Un premier danger auquel le musée qui prend en compte un patrimoine immatériel du témoignage doit faire face est le risque de

37. D'Isère et du Maghreb - Mémoires d'immigrés, éd. Musée dauphinois, Grenoble, 1999.

38. Pour une vue d'ensemble de ces questions voir Laurier Turgeon 2003 er les numéros thématiques qu'il a consacrés, avec Élise Dubuc, dans Anthropologie et sociétés (2004) et Ethnologies (2002). 
tourner au porte-parole de mémoires particulières. Ces musées créés sur les lieux mêmes des drames qu'ils commémorent répondent à une conjoncture historiographique marquée par ce qu'Annette Wieviorka a appelé "l'ère du témoin" (Becker 1998). Cette situation entraîne des difficultés classiques de réalisation, qui requièrent des supports matériels des mémoires locales, la retranscription et l'interprétation de l'oralité, et l'exposition d'objets ou de phénomènes observables. Pour l'historien, remarque Annette Wieviorka, un « témoignage s'adresse au cœur et non pas à la raison. Il suscite la compassion, la piété, l'indignation, la révolte parfois" (1998), et pose la question du rapport de la rigueur du récit historique à la pression des émotions. Un autre des risques d'une muséologie de l'histoire contemporaine est alors, comme le regrette l'anthropologue Jean-Yves Boursier, de ne porter que des messages bien-pensants : "l'horreur de la guerre, le dégoût de la barbarie, la compassion pour ses victimes, mais aussi la déshistoricisation de la Résistance, immergée dans l'éternel combat du Bien contre le Mal "(2005: 162). Ainsi, ajoute-t-il, "nous sommes passés de l'altérité (le musée supporté par un groupe) à la norme et au discours moral, appuyés par des opérations de communication" (241). Le propos peut être généralisé à certains traits des politiques culturelles contemporaines.

\section{Patrimoine immatériel et politiques culturelles}

La place de l'ethnologie dans les projets culturels menés à différentes échelles politiques a été marquée, après la génération des écomusées, par l'élaboration récente de "territoires de projets » de plus en plus nombreux et divers. La mise en valeur du patrimoine immatériel, et son rapport aux musées, figure explicitement en particulier dans le Programme de développement rural de la Corse 2007-2013, dans les attendus du Conseil économique et social régional Rhône-Alpes, dans la réflexion sur le territoire de projet du Pays de Vichy-Auvergne, dans le projet de territoire Pays basque 2020, dans la réflexion menée en Languedoc-Roussillon, etc. Dans ce dernier cas, la création en 2003 du Parc naturel régional de la Narbonnaise a entraîné différents modes de production du territoire, dont l'opération "Les archives du sensible ", centrée sur le patrimoine immatériel en 2006. Le Languedoc-Roussillon, lieu d'aménagements touristiques importants dans les années 1960, a connu en retour une très forte revendication régionaliste sur le modede la sauvegarde de la langue d'oc, des traditions et des savoir-faire. 
Après une politique du conseiller ethnologique de la DRAC centrée sur le patrimoine maritime, l'opération en cours :

désigne une entreprise de connaissance des pratiques les plus fragiles, des relations symboliques les plus discrètes entretenues par une partie de la population avec son territoire. ... sa relation à la consommation touristique est ambivalente : née du désir d'affirmer une résistance de l'" autochtonie " face au tourisme de masse, elle en vient à proposer une autre façon de rencontrer le pays, ou plutôt l'arrière-pays dont l'invisibilité, par rapport aux flux touristiques majeurs se concentrant sur le littoral, garantirait "l'authenticité " (Ciarcia 2006).

Un tel exemple est très révélateur des constructions identitaires réinventées souvent passées, ces dernières années, de l'espace des Parcs et des écomusées au cadre fourni par divers "territoires de projet " liés aux contrats de pays. L'analyse des projets de pays actuels montre ainsi que la thématique de la "valorisation des ressourcesnaturelles et culturelles " apparaît dans $41 \%$ des thèmes proposés, et que sur les 97 dossiers comprenant des projets d'ordre culturel - sur 140 - 70 font apparaître des mesures liées à la valorisation du patrimoine (Landel et Treillet 2005). C'est dire combien le jeu «dialectique " entre «les recompositions territoriales et l'invention de politiques culturelles nouvelles car conçues à partir des ressources des territoires » est devenu crucial.

Sylvie Grenet, chargée de mission à la mission ethnologie du ministère de la Culture, a remarqué lors d'une conférence donnée à l'été 2006 que, dans la logique de la Convention, "le soutien des communautés par les États ne saurait obérer les constructions identitaires des pratiques et des savoirs portés par ces mêmes communautés .... Le patrimoinc culturel immatériel apparaît donc comme une notion certes sociétale, mais également avant tout politique, voire stratégique, pour les communautés comme pour les États " ${ }^{39}$. Tel est, de toute évidence, l'un des enjeux cruciaux dans les années à venir d'une interaction État/ communautés/individus encore difficile à concevoir dans la tradition administrative française. On peut évoquer à cet égard la possibilité d'une coexistence de langues régionales avec la langue française, objet d'un débat récurrent, repris dans de nombreux rapports et envisagé par la Délégation générale à la langue française et aux française et aux langues de France ${ }^{39}$.

39. htrp://www.vie-publique.fr/politiques-publiques/politique-patrimoine/ protection-patrimoine/patrimoine-immateriel/ 
À l'échelle des pays, pour le dire rapidement, le dessein semble poursuivre surtout "la quête impossible du géosymbole", reléguant dans l'oubli, à chaque fois, une part constitutive de la société et du territoire $^{40}$. À l'échelle nationale, et au moment où le Ministère de la Culture, confronté à des coupes budgétaires et à une crise de légitimité, ausculté par de nombreux rapports de commissions (voir Rigaud 1996), paraît devoir remettre ses missions sur le métier, le patrimoine immatériel ajoute les difficultés de sa prise en charge à une série de questions irrésolues. Quant à l'ethnologie française, elle est directement interrogée par le principe d'une politique du patrimoine immatériel qui s'exerce de la posture documentaire à la posture participative, passant de l'inventaire stricto sensu à la construction de dispositifs permettant l'analyse de la caractérisation patrimoniale.

On en voit la manifestation dans les deux inventaires aujourd'hui en cours à la suite de l'exigence de la convention sur le patrimoine culturel immatériel - qui, à l'article 12, prévoit que les pays doivent dresser des inventaires pour "assurer l'identification en vue de la sauvegarde ", et "la viabilité " " . Le premier inventaire, lancé en août 2007, se veut un inventaire des inventaires existant: il reprend une tradition antérieure de compilation de données disponibles dans divers dossiers thématiques ${ }^{42}$. Le second inventaire s'affirme, selon le propos ministériel, "plus proche de l'esprit de la convention", qui "vise à répertorier des pratiques vivantes, en collaboration avec le concours des communautés, des groupes et des individus". Il a commencé en mars 2008, et s'appuie sur les outils mis en œuvre par l'Inventaire des ressources ethnologiques du patrimoine immatériel (IREPI) de l'Université Laval à Québec. Pour l'instant l'entreprise mobilise quatre partenaires, la Société d'Encouragement des Métiers d'Art (SEMA), dépendant du ministère de l'industrie, l'Institut Occitan ( $\mathrm{InOc}$ ), le Centre des Musiques Traditionnelles (CMDT) de Corse et le LAHIC (Laboratoire d'Anthropologie et d'Histoire de l'Institution de la Culture,

40. On trouvera une série d'analyses concordantes dans Valérie Jousseaume et Olivier David (2007).

41. "Pour assurer l'identification en vue de la sauvegarde, chaque État partie dresse, de façon adaptée à sa situation, un ou plusieurs inventaires du patrimoine culturel immatériel présent sur son territoire. Ces inventaires font l'objet d'une mise à jour régulière ".

42. On le consulte à l'adresse http://www.culture.gouv.fr/culture/dp/ethno_spci/ invent_invent.htm 
unité mixte CNRS-Ministère de la Culture) $)^{43}$. Dans ce cadre, le projet actuel est "de faire se croiser les principes de l'inventaire français, et ceux d'une méthode testée actuellement au Vietnam, spécifiquement dédiée à la question de la participation des communautés» ${ }^{44}$.

Dans le cas de la SEMA le projet est un inventaire des métiers d'art rares en France lancé en mars 2008, à la fois pour être inclus dans l'inventaire du patrimoine culturel immatériel, et pour assurer le développement et la valorisation de ces métiers ${ }^{45}$. La démarche $s^{\prime}$ inscrit de facto dans les débats contemporains sur les politiques publiques, sinon sur les ressources de l'immatériel dans l'économie que l'on a présentés en introduction. La Cour des comptes a en effet, en mars 2007, critiqué l'activité de la SEMA auprès du Ministre de l'industrie, du commerce et de l'artisanat et des PME, au motif que l'association (sous régime de la loi commune dite 1901) devait développer son rôle de prestataire de services, et non plus agir principalement pour le compte de l'État dans un cadre conventionnel, en particulier afin de grossir le niveau de ses ressources propres, jugé très insuffisant. Cette orientation implique de trouver de nouvelles ressources auprès du commerce des métiers d'art, en répondant à la demande du marché, ou plutôt en la suscitant, et en offrant des services marchands aux métiers - ce que le secrétaire d'État accepte dans sa réponse à la Cour, tout en défendant les financements d'État "dans le cadre d'orientationsarrêtées de concert avec les pouvoirs publics.$^{46} \mathrm{Or}$ cet aggiornamento en forme de nouvelle gouvernance publique recoupe largement la problématique mise en avant par la convention, celle du rôle des communautés, groupes ou individus. Dans le contexte français, en effet, l'inventaire passe traditionnellement par l'intermédiaire de

43. "La SEMA entreprend un inventaire des métiers d'art rares en France, l'InOc travaille sur un inventaire des expressions occitanes en région Aquitaine, le CMDT de Corse entame une recherche sur l'inventaire de cantu in paghjella, une forme de polyphonie, et une chercheuse du LAHIC (Chiara Bortolotto) est chargée d'une étude sur la faisabilité d'un inventaire des pratiques culturelles des communautés immigrées en Ile-de-France."

44. On suit ici l'exposé des motifs fourni par la note Les inventaires en France, http:/ /www.culture.gouv.fr/culture/dp/ethno_spci/invent_invent.htm. Voir aussi, sur le site du Lahic, http://www.lahic.cnrs.fr/spip.php?article308, les contributions de Jean-Louis Tornatore 2007, et de Gaetano Ciarcia 2007.

45. Voir le résultat de l'inventaire en Ile de France sur http://www.metiersrares.com/

46. Rapport public annuel de la cour des comptes, 2009, "La société d'encouragement aux métiers d'art », pp. 153-158. Voir http://www.ccomptes.fr/ fr/CC/Sommaire-21.html 
structures institutionnelles, responsables de l'expertise et de la validation, " notamment pour discerner, au sein des pratiques vivantes, celles quirelèvent d'une revitalisation artificielle, et celles qui, sous des dehors parfois commerciaux, ou folklorisants, sont révélateurs de réels espaces d'expression et de production de pratiques anciennes renouvelées $" .47$

La légitimité de la conservation et de la mise en valeur du patrimoine en tout ou partie immatériel repose aujourd'hui sur l'intérêt général du public - et celui, spécifique, de communautés - pour un travail et ses représentations, pour des savoir-faire et des pratiques, des habitudes - qui peuvent le cas échéant être présentés sur un marché devenu global. Parallèlement, l'intérêt savant porté aux hauts lieux, aux monuments historiques, aux territoires touchés par la conversion patrimoniale se concentre sur leur réception: l'habitant et le visiteur requièrent peu à peu toute l'attention, dans l'examen des modalités d'une relation censée "domestiquer l'histoire"(Fabre 2000). On a souligné, dans cette perspective, que l'intérêt des musées d'objets est de demeurer ouverts aux multiples discours de la mémoire - contre, à la fois, une marchandisation de l'histoire-spectacle qui exclut l'approche critique, et une fusion du propos muséographique et du savoir historien qui suscite en retour une frustration de la mémoire (Sherman 1995). On constate plus généralement les limites d'une protection qui s'en tient au bâtiment, au matériel, indépendamment d'une histoire personnelle qui s'essaie à construire un lien - ainsi dans le cas des néoruraux et des entrepreneurs de patrimoine en résidence "secondaire " (Ortar 2005). Le rapport savant au patrimoine immatériel s'inscrit aujourd'hui, en d'autres termes, dans une lecture des constructions toujours plus ou moins volatiles de l'identité et des traditions, entre continuité d'intentions et déplacement des horizons de référence. Il vient dans beaucoup de cas s'ajouter à des dispositifs déjà existants, qui ont pris en charge parfois depuis près de deux siècles les biens matériels, meubles et immeubles, cadres et outils de ce qu'on appelait naguère les productions spirituelles.

Surtout, il vient renforcer ce qui fait la spécificité sans doute du musée d'ethnologie, dépourvu de "trésors", quoi qu'il en ait: la consécration d'un territoire. De ce point de vue, la situation de la France est paradoxale. Solidement identifiée à un territoire national -

47. Les inventaires, voir note 44. 
l'Hexagone, son ultime représentation, est au plein sens du terme un lieu de mémoire et la pensée des frontières a profondément marqué l'héritage historiographique et intellectuel (Weber 1986 ; Nordman 1998) - la France n'en est pas moins aux prises, depuis près de deux siècles, avec un vertige des découpages territoriaux ${ }^{48}$. Le constat récent d'un géographe est communément partagé : "Ce foisonnement des recompositions territoriales déroute souvent le citoyen et répond mal à son souci d'être associé aux décisions qui concernent son cadre de vie " (Marconis $2006: 12$ ). La dernière figure de l'usage politique du territoire de projet, le pays, dans ses virtualités de promouvoir une véritable démocratie de proximité participative, parât pouvoir fournir de ce point de vue un point d'ancrage aux inventaires de manifestations du patrimoine immatériel, après l'utopie de l'écomusée, notamment. Pour autant, les fragilités de la démarche patrimoniale appliquée à l'immatériel sont évidentes: les risques d'un devenir emblématique et sentimental du patrimoine immatériel sont bien présents, qui éloigneraient la France du défi savant que représentait l'affirmation d'un patrimoine ethnologique au cours de la décennie 1980. L'échec éventuel pèserait dès lors sur le processus d'adoption de normes internationales de définition et de gouvernance du patrimoine, substituées au legs national d'une administration centralisée de la connaissance disciplinaire et de la gestion muséographique.

48. Les premières conclusions du comité Balladur (le 24 fév 2009) chargé de proposer un nouveau découpage spatial de la France ont ravivé les clivages à cet égard. 


\section{Références}

Barbe, Noël, 2007, "Le déploreur de l'utilité, l'expert fraternel et l'inventeur de science détaché. Production de savoir et action culturelle». Ethnographiques.org, 12 [en ligne] http:// www.ethnographiques.org/

Baré, Jean-François (dir.), 1995, Les applications de l'anthropologie. Un essai de réflexion collective depuis la France. Paris, Karthala.

Maurice Barrès, 1913, La grande pitié des églises de France, Paris.

Bazin, Jean, 2002, "N'importe quoi». Dans Marc-Olivier Gonseth, Jacques Hainard et Roland Khaer (dir.), Le Musée cannibale. Neuchâtel, Musée d'ethnographie.

Becker, Anette, 1998, "Musées ouverts, traces des guerres dans le paysage ", dans Marie-Hélène Joly et Thomas, Compère-Morel (coord.), Des musées d'histoire pour l'avenir, actes du colloque de Péronne. Paris, Noesis.

Benzaïd, R., 1980, L'ethnologie de la France. Besoins et projets. Paris, La Documentation Française.

Boursier, Jean-Yves (dir.), 2005, Musées de guerre et mémoriaux. Politiques de la mémoire. Paris, Éditions de la Maison des sciences de l'homme. Bromberger, Christian, 1996, "Ethnologie, patrimoine, identité. Y a-til une spécificité de la situation française?", dans Daniel Fabre (dir.), L'Europe Entre Cultures et Nations, Cahier d'ethnologie de la France, 10 : 16-18. Paris, Éditions de la Maison des Sciences de l'Homme. 2007, "D'un musée... l'autre. Réflexions d'un observateur participant ". Etnográfica, 11 (2) : 407-420.

Bruce, Albert, 1995, "Anthropologie appliquée ou "anthropologie impliquée" ? Ethnographie, minorités et développement ", dans Jean-François Baré (dir.), Les applications de l'anthropologie. Un essai de réflexion collective depuis la France: 87-118. Paris, Karthala.

Charles-Brun, Jean, 1911, Le régionalisme. Paris, Bloud et Cie.

Butler, Shelly Ruth, 2007, Contested Representations. Revisiting "Into the Heart of Africa ». Toronto, Broadview Press.

Ciarcia, Gaetano, 1990, La perte durable. DAPA, Ministère de la culture. Chiva, Isaac, 1990, "Le patrimoine ethnologique. L'exemple de la France ». Encyclopaedia Universalis, Symposium: 229-241.

Clair, Jean, 2007, Malaise dans les musées. Paris, Flammarion.

Colardelle, Michel, 2001, Le Musée et le Centre Interdisciplinaire d'études des civilisations de l'Europe et de la Méditerranée, Étude préalable pour un projet de "délocalisation " du MNATP-CEF de Paris à Marseille. http://www.culture.gouv.fr/culture/actualites/rapports/colardelle/ sommaire.htm. 
Cornu, Marie, 2003, "Droit des biens culturels et des archives». En ligne sur Legamedia.

Cuisenier, Jean, 2006, L'héritage de nos pères. Paris, La Martinière. et Martine Segalen, 1986, Ethnologie de la France. Paris, PUF.

Debaene, Vincent, 2006, "Étudier des états de conscience". La réinvention du terrain par l'ethnologie, 1925-1939». L'Homme, $179: 7-62$.

Debary, Octave et Laurier Turgeon (dir.), 2007, Objets 83 Mémoires. Paris, Éditions de la Maison des Sciences de l'Homme.

Derèze, Gérard, 2005, "De la culture populaire au patrimoine immatériel ». Hermès 42 : 47-53.

Dubuisson, Jean, 2008, Jean Dubuisson par lui-même. Texte établi par Armelle Lavalou à partir d'entretiens réalisés en 2006 et 2007. Paris, Linteau.

Fabian, Johannes, 2004, "On Recognizing Things. The "Ethnic Artefact" and the "Ethnographic Object"». L'Homme, $174: 47$. 60.

Fabre, Daniel, 1986, «L'ethnologue et ses sources». Terrain, $7:$ 3-12. 2000, "Ancienneté, altérité, autochtonie », dans Daniel Fabre (dir.), Domestiquer l'histoire. Ethnologie des monuments historiques. Paris, Éditions de la Maison des sciences de l'homme. 2006, "Le patrimoine culturel immatériel. Notes sur la conjoncture française », http://www.lahic.cnrs.frspip.php?article306. Fleury, E., 1988, "Avant-propos ». Terrain 11: 5-7.

Georgel, Chantal (dir.), 1994, La jeunesse des musées. Les musées de France au XIXe siècle. Paris, Musée d'Orsay.

Gerson, Stéphane, 2003, "Une France locale. The Local Past in Recent French Scholarship ». French Historical Studies 26 : 539-559.

Grenet, Sylvie, 2006, "Problématiques et enjeux du patrimoine culturel immatériel au Ministère de la culture ", Communication donnée lors des rencontres Patrimoine culturel immatériel et transmission la polyphonie corse traditionnelle peut-elle disparaitre? Centre des musiques traditionnelles corses, 22 et 23 juin, Ajaccio.

Guibal, Jean, 1999, "La diversité des cultures au Musée dauphinois de Grenoble », dans Emilia Vaillant et Germain Viatte (dir.), Le musée et les cultures $d u$ monde: 257-259. Paris: École nationale du patrimoine.

Green, Nancy, L., 2007, " History at Large. A French Ellis Island? Museums, Memory and History in France and the United States ». History Workshop Journal, 63 : 239-25.3. 
Hoyt, David, L., 2001, "The Reanimation of the Primitive. Fin-deSiècle Ethnographic Discourse in Western Europe ". History of Science $39:$ 331-354.

, 2006, "Dialects of modernization in France and Italy, 1865. 1900 ", dans David L. Hoyt et Karen Oslund, (dir.), The Study of Language and the Politics of Community in Global Context : 85-118. Lanham (MD), Lexington Books.

Idjéraoui Linda, Jean Davallon, 2002, "Le témoignage historique comme objet de musée?". Recherches récentes en sciences de l'information, actes de colloque international, 21 et 22 mars, Toulouse, éditions Adbs.

Jadé, Mariannick, 2005, «Le patrimoine immatériel. Quels enjeux pour les musées ? ", dans Lettre du Comité national français. ICOM-France, 29.

Jamin, Jean, 1991, Les musées d'anthropologie sont-ils dépassés? dans Le futur antérieur des musées. Paris, Éditions du Renard.

$7-10$. 2004, "La règle de la boîte de conserve ». L'Homme 170:

Joly, Marie-Hélène et Thomas Compère-Morel (dir.), 1998, Des musées d'histoire pour l'avenir, actes du colloque de Péronne. Paris, Noesis. Jousseaume, Valérie et Olivier David, 2007, "Patrimoine, culture et construction identitaire dans les territoires ruraux ». Norois 204 : 7-9.

Joutard, Philippe, 1983, Ces voix qui nous viennent du passé. Paris, Hachette.

Kavanagh, Gaynor, 1990, History Curatorship. Leicester, Leicester University Press.

Laferté, Gilles et Nicolas Renahy, 2003, "Campagnes de tous nos désirs"... d'ethnologues ". L'Homme, 166 : 225-234.

2003, "L'ethnologue face aux usages sociaux de l'ethnologie». L'Homme 166 : 239-240.

Landel, Pierre-Antoine et Philippe Treillet, 2005, «La place de la culture dans la recomposition des territoires. Le cas des pays issus de la loi Voynet". Rencontres annuelles des Conseils de développement des Pays de Champagne-Ardenne, notes dactylographiées.

Le Goff, Jacques, 1977, Histoire et Mémoire. Paris, Gallimard. , 1997, "Préface à Marc Bloch », dans Marc Bloch, Apologie pour l'histoire ou Métier d'historien. Paris, Armand Colin.

Lenclud, Gérard, 1995, "La question de l'application dans la tradition anthropologique française", dans Jean-François Bare (dir.), Les 
applications de l'anthropologie. Un essai de réflexion collective depuis la France: 65-84. Paris, Karthala.

Mallet-Poujol, Nathalie et Jean-Michel Bruguière, "Quand la Cour de cassation abuse du droit de propriété sur l'immatériel ». Droit et patrimoine 91: 84-106.

Marconis, Robert, 2006, France. Recompositions territoriales. Paris, La Documentation française.

Micoud, André, Laurence Bérard, Philippe Marchenay et Michel Rautenberg, 2003, "Et si nous prenions nos désirs en compte?". L'Homme 166 : 235-238.

Mohen, Jean-Pierre, 2004, Le nouveau musée de l'Homme. Paris, Odile Jacob-Muséum national d'histoire naturelle.

Nordman, Daniel, 1998, Frontières de France. De l'espace au territoire, XVIe-XIXe siècles. Paris, Gallimard.

Ortar, Nathalie, 2005, «Restaurer sa maison à l'ombre d'un patrimoine», dans Maria Gravari-Barbas, Habiter le patrimoine. Enjeux-approchevécu: 41-50. Rennes, Presses universitaires de Rennes.

Pommier, Édouard, 1991, "Prolifération du musée ", dans Le Débat $65: 144-149$.

Poulard, Frédéric, 2007, «Les écomusées. Participation des habitants et prise en compte des publics». Ethnologie française XXVII (3): 551-557.

Poulot, Dominique, 2008, "Gloires et opprobres politiques au musée». Sociétés 8 Représentations 26: 197-217.

Price, Sally, 2007, Paris primitive. Jacques Chirac's Museum on the Quai Branly. Chicago, University of Chicago Press.

Raphaël Freddy et Geneviève Herberich-Marx, 1987, "Le musée, provocation de la mémoire ». Ethnologie française 17 (1) : 87-95.

Rigaud, Jacques, 1996, Pour une refondation de la politique culturelle.

Paris, La Documentation française.

Segalen, Martine, (dir.), 1989, L'autre et le semblable. Paris, Presses du CNRS.

2005, Vie d'un musée, 1937-2005. Paris, Stock.

Schéma directeur de la recherche en sciences humaines 2005-2008 dans les musées nationaux. Paris.

Sherman, Daniel J., 1995, "Objects of Memory. History and Narrative in French War Museums". French Historical Studies 19 (1) : 49-74.

Rivière, Georges-Henry, 1985, "Définition évolutive de l'écomusée ", Museum 148, XXXVII, 4 : 182-183. 
Tornatore, Jean-Louis, 2007, "Qu'est ce qu'un ethnologue politisé ? Expertise et engagement en socio-anthropologie de l'activité patrimoniale ». Ethnographiques.org, 12 (www.ethnographiques.org). Turgeon, Laurier, 2003, Patrimoines métissés. Contextes coloniaux et postcoloniaux. Paris et Québec, Éditions de la Maison des sciences de l'homme et Presses de l'Université Laval.

Van Gennep, Arnold, 1914, "Quelques lacunes de l'ethnographie actuelle ", dans Religions, Mœurs et Légendes. Essais d'ethnographie et de linguistique, 5e série: 9-25. Paris, Mercure de France. , 1924 a, Le folklore. Paris, Stock.

1924 b, La culture moderne, Paris, Stock.

Varine, Hugues de, 1986, Nouvelles Muséologies. Macon, Éditions W. I M.N.E.S.

, 1993, Conférence prononcée le 15 October, à l'Université d'Utrecht, "Tomorrow's Community Museums », à l'occasion du prix du musée européen de l'année (www.europeanmuseumforum. eu/documents/annual_lectures/Hugues_de_Varine.pdf).

Weber, Eugen, 1986, "L'hexagone ", dans Pierre Nora (dir.), Les lieux de mémoire, tome 2, vol. 2: 97-116. Paris, Gallimard.

Weber, Florence, 2003, Pour une histoire des politiques du patrimoine. Paris, Comité d'histoire du ministère de la culture.

Whitmarsh, Andrew, 2001, "We will remember them." Memory and Commemoration in War Museums ». Journal of Conservation and Museum Studies 7 : 1-15. 